Научная статья

УДК 378

DOI: $10.17213 / 2075-2067-2021-6-187-195$

\title{
ВОЗДЕЙСТВИЕ ЦИФРОВЫХ РЕСУРСОВ НА РАЗВИТИЕ РЕГИОНАЛЬНЫХ СИСТЕМ В РОССИИ
}

\author{
Михаил Михайлович Куликов ${ }^{1 \bowtie}$, Мария Анатольевна Комиссарова $^{2}$, \\ Алина Владимировна Комарова \\ ${ }^{1,2,3}$ Южно-Российский государственный политехнический университет (НПИ) \\ имени М. И. Платова, Новочеркасск, Россия \\ ${ }^{1}$ kulikovmichael@mail.ru ${ }^{\bowtie}$,ORCID:0000-0002-4139-9391, \\ AuthorID РИНЦ: 360563, Scopus Author ID: 57209222679 \\ ${ }^{2}$ mari543@yandex.ru, ORCID: 0000-0002-8862-4445, \\ AuthorID РИНЦ: 348870, Scopus Author ID: 57000351700 \\ ${ }^{3}$ komi_was_where@mail.ru, ORCID:0000-0002-2924-088X
}

\begin{abstract}
Аннотация. Цель работы - выявление специфики применения циифровых ресурсов в различных сферах деятельности и их положительное влияние на развитие России.

Методологию исследования представляют нормативные акты, статистические данные Федеральной службы государственной статистики, научные публикации по ијифровизации российских регионов и внедрению циирровых платформ, аналитические данные сайтов национальных проектов России, данные Единой межведомственной информационно-статистической системы, а также структурный анализ и элементы сравнительного анализа. Применение данных методов и подходов позволяет изучить используемые в настоящий момент ицифровые ресурсы, их достоинства и недостатки, спрогнозировать предполагаемые результаты от их внедрения.
\end{abstract}

Результаты исследования. Одним из важных результатов является полученный анализ внедрения иифровых ресурсов на предприятиях в различных сферах деятельности и отражение их применения на уровне регионального развития. Цифровая трансформаџия регионов России в последние годы значительно возросла в связи с переходом к использованию цифровых технологий на предприятиях, в государственных и муниципальных учреждениях. Однако в настоящий момент между субъектами РФ существует разрыв в показателях цифрового развития и применения цифровых ресурсов. Говоря о воздействии циирровых ресурсов на развитие региональных систем, стоит подчеркнуть необходимость выравнивания показателей ичифровизации между регионами, а также между столицами субъектов и других городов в соответствующем субъекте, равной доступности к Интернет-сети и увеличения коэффищиента развитости общества в области использования и применения иифровых технологий.

Перспективу исследования составляет анализ внедрения циирровых проектов, которые оказали положительную динамику на развитие субъектов Российской Федераџии.

Ключевые слова: циифровизация, ичифровые технологии, национальные проекты, ичифровые сервисы, ичифровой регион

Для цитирования: Куликов М. М., Комиссарова М. А., Комарова А. В. Воздействие иифровых ресурсов на развитие региональных систем в России // Вестник Южно-

(C) Куликов М.М., Комиссарова М.А., Комарова А. В., 2021 
Российского государственного технического университета. Серия: Соииальноэкономические науки. 2021. T. 14, № 6. C. 187-195. http://dx.doi.org/10.17213/2075-20672021-6-187-195.

Original article

\title{
THE IMPACT OF DIGITAL RESOURCES ON THE DEVELOPMENT OF REGIONAL SYSTEMS IN RUSSIA
}

\author{
Mikhail M. Kulikov ${ }^{1 凶}$, Maria A. Komissarova ${ }^{2}$, Alina V. Komarova ${ }^{3}$ \\ ${ }^{1,2,3}$ Platov South Russian State Polytechnic University (NPI), Novocherkassk, Russia \\ ${ }^{1}$ kulikovmichael@mail.ru ${ }^{\bowtie}$,ORCID: 0000-0002-4139-9391, \\ AuthorID RSCI: 360563, Scopus Author ID: 57209222679 \\ 2mari543@yandex.ru, ORCID:0000-0002-8862-4445, \\ AuthorID RSCI: 348870 , Scopus Author ID: 57000351700 \\ ${ }^{3}$ komi_was_where@mail.ru, ORCID:0000-0002-2924-088X
}

\begin{abstract}
The purpose of the study is to reveal the specifics of using digital resources in various fields of activity and their positive impact on the development of Russia.

The methodological base of the study is represented regulations, statistical data Federal State Statistics Service, scientific publications on digitalization of Russian regions and the introduction of digital platforms, analytical data of the websites of national projects Russia, data of Unified interdepartmental information and statistical system, as well as structural analysis and elements of comparative analysis. The application of these methods and approaches allows to study the applied in the digital resources currently, their advantages and disadvantages, and predict the expected results from its implementation.

Research results. The important result is the obtained analysis of the implementation of digital resources at enterprises in various fields of activity and the reflection of their application at the level of regional development. The digital transformation of Russian regions in recent years has increased significantly due to the transition to the use of digital technologies in enterprises, state and municipal institutions. However, at the moment, there is a gap between the constituent entities of the Russian Federation in index of digital development and the use of digital resources. Speaking about the impact of digital resources on the development of regional systems, it is worth emphasizing the need to align digitalization indicators between regions, as well as between the capitals of constituent entities and other cities in the corresponding entity, equal accessibility to the Internet network and an increase in the coefficient of development of society in the use and application of digital technologies.

The prospect of the study is the analysis of the introduction of digital projects that have positive dynamics in the development of the constituent entities of the Russian Federation.

Keywords: digitalization, IT-technologies, national projects, digital services, digital region

For citation: Kulikov M. M., Komissarova M. A., Komarova A. V. The impact of digital resources on the development of regional systems in Russia // Bulletin of the South Russian State Technical University. Series: Socio-economic Sciences. 2021; 14(6): 187-195. (In Russ.). http:// dx.doi.org/10.17213/2075-2067-2021-6-187-195.
\end{abstract}


Введение. В последние годы государство ставит акцент на внедрение цифровых технологий и повышение цифрового развития в субъектах Российской Федерации. Такой интерес связан с национальным проектом «Цифровая экономика», который объединяет развитие информационной инфраструктуры, цифрового государственного управления, цифровых технологий, разработок в области искусственного интеллекта и подготовку кадров, что невозможно без концентрации полученного и накопленного опыта различных предприятий и компаний российских регионов. Здравоохранение, экология, наука, туризм, культура, транспорт - населенные пункты уже совершили или совершают переход к применению цифровых ресурсов в данных отраслях (рис. 1). В условиях пандемии большой интерес вызвала сфера образования и возможность получения гражданами государственных и муниципальных услуг в электронном виде, при этом создание «умного города» является перспективной сферой для развития региональной цифровой экономики.

Методологическая и эмпирическая база исследования. Основу работы составили статистические материалы и публикации в периодических изданиях, затрагивающие различные аспекты исследуемой проблемы. Особое внимание в работе уделяется практическому применению цифровых технологий в рамках реализации проектов, которые могут быть отнесены к программе «Цифровая экономика» ${ }^{1}$, выступать в роли достижения Целей устойчивого развития [11] и регионального развития ${ }^{2}$.

Методологической основой данного исследования является статистический метод и метод обобщения нормативных, научных и практических материалов, которые позволили комплексно подойти к изучению проблематики.
Эмпирическую базу исследования составили данные, размещенные на сайте Федеральной службы государственной статистики и Единой межведомственной информационно-статистической системы, а также информация сайта «Национальные проекты».

Воздействие цифровых ресурсов на развитие региональных систем в России. В настоящее время программа «Цифровая экономика» насчитывает большое количество проектов, реализованных российскими регионами ${ }^{3}$. В числе данных проектов особое место занимает внедрение цифровых технологий в транспортную инфраструктуру города, а также в систему жилищно-коммунального хозяйства. Ярким примером выступает «Государственная информационная система жилищно-коммунального хозяйства», которая насчитывает свыше 19 миллионов жилых домов, около 1 миллиона многоквартирных домов и более 105 тысяч зарегистрированных организаций ${ }^{4}$.

Говоря о проектах в области применения цифровых технологий в городскую транспортную инфраструктуру и систему жилищно-коммунального хозяйства, стоит отметить Новгородскую область и Республику Северная Осетия. Новгородская область разработала и успешно применила систему по контролю приборов учета коммунальных ресурсов. Кроме того, регион использует технологию больших данных для подсчета количества туристов в целях развития туризма. Северная Осетия разработала интеллектуальную платформу в сфере жилищно-коммунального хозяйства. Платформа характеризуется возможностью ведения «прозрачного» учета суммы оплаты за ресурсы ЖКХ, при этом потребители могут произвести оплату через Интернет. Также цифровые технологии применяет Алтайский край. Например, в регионе

1 Интернет-ресурс о планах развития Российской Федерации и мерах по улучшению качества жизни людей «Национальные проекты» [Электронный ресурс]. URL: https://национальныепроекты.рф (дата обращения: 06.08.2021 г.).

2 Как российские регионы развивают цифровую экономику от 20.08.2018. Ведущее государственное информационное агентство Российской Федерации «ТАCС» [Электронный pecypc]. URL: https://tass.ru (дата обращения: 02.10.2021 г.).

3 Интернет-ресурс о планах развития Российской Федерации и мерах по улучшению качества жизни людей «Национальные проекты» [Электронный ресурс]. URL: https://национальныепроекты.рф (дата обращения: 06.08.2021 г.).

4 Государственная информационная система жилищно-коммунального хозяйства [Электронный ресурс]. URL: https://dom.gosuslugi.ru (дата обращения: 02.10.2021 г.). 


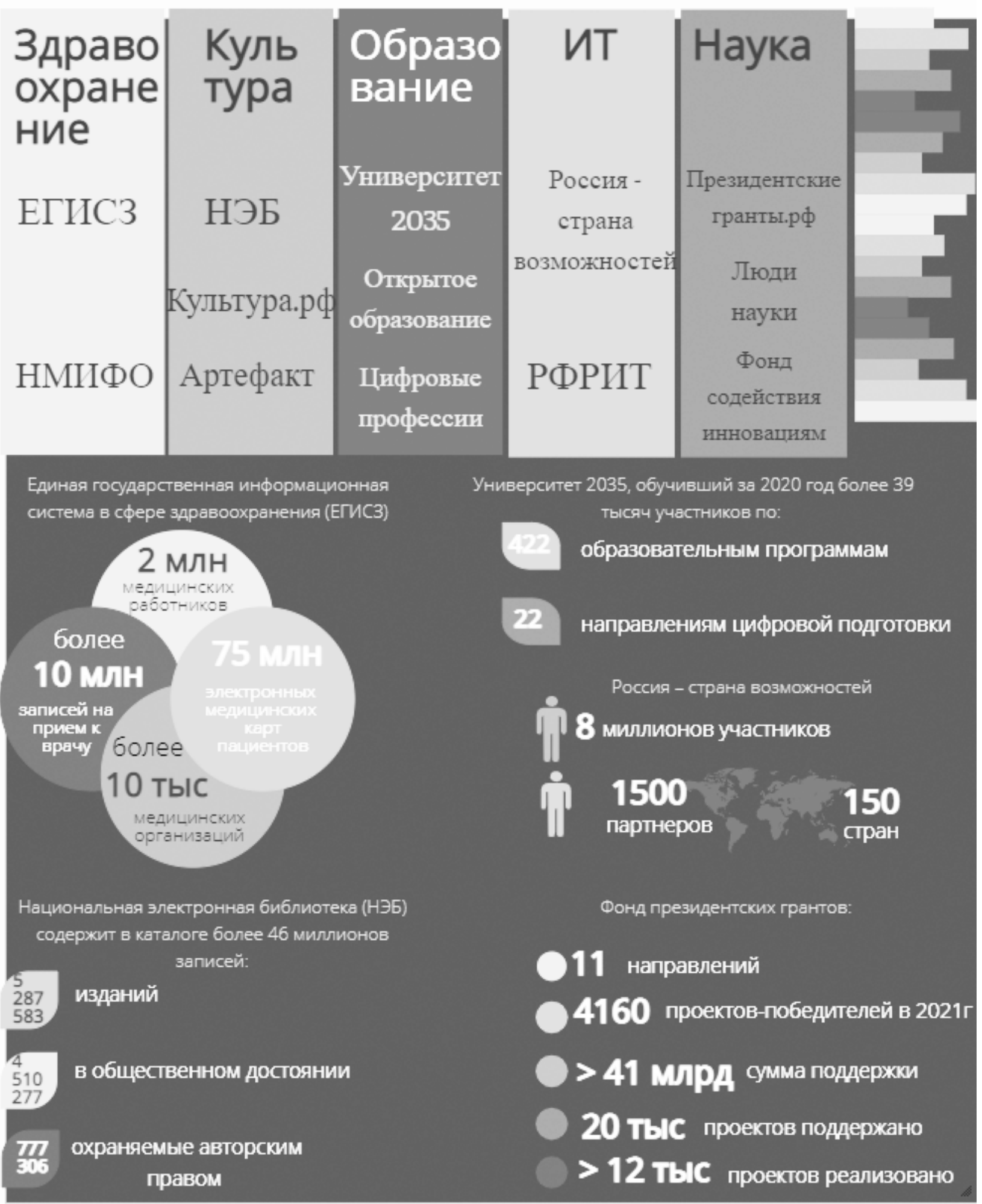

Рис. 1. Аналитика внедрения цифровых сервисов на примере пяти отраслей (разработано авторами)

Fig. 1. Analytics of digital services implementation on the example of five industries (developed by the authors) 
используют спутники для мониторинга хода полевых работ ${ }^{5}$.

Благодаря цифровым технологиям некоторые российские регионы способствуют росту социально-экономического развития. Так, во время проведения в августе 2021 года сельскохозяйственной микропереписи был проведен в 6 субъектах России эксперимент с беспилотными летательными аппаратами ${ }^{6}$. Одной из важнейших инноваций стало использование фотосъемки с дронов и спутниковый мониторинг. Кроме того, были использованы планшеты, сократившие время на сбор информации. Такой подход позволил исследовать более 140 тысяч крестьянскофермерских хозяйств, а также 16 миллионов личных подсобных хозяйств. При этом было обработано большое количество информации, окончательные показатели которой будут готовы уже в I квартале 2022 года.

В условиях ограничений следует отметить важность применения цифровых технологий при проведении выборов 19 сентября 2021 года и проведении Всероссийской переписи населения (далее - ВПН-2020), которая пройдет с 15 октября по 14 ноября 2021 года. Благодаря сервису «Дистанционное электронное голосование» (ДЭГ) жители 7 субъектов Российской Федерации смогли принять участие в голосовании из любой точки мира, не посещая избирательный участок ${ }^{7}$. По данным Центральной избирательной комиссии Российской Федерации (ЦИК), дистанционно проголосовали 2535978 человек, что составляет четверть от проживающих в 7 субъектах избирателей, имеющих подтвержденные записи на портале «Госуслуги» ${ }^{8}$.

«Страна-2020» сообщает о главном нововведении ВПН-2020 - возможности самостоятельного заполнения электронного переписного листа через ЕПГУ «Госуслуги» ${ }^{9}$ По данным Росстата, около 90\% данных предполагается собрать в цифровом формате с помощью ЕПГУ «Госуслуги», компьютеров в центрах государственных и муниципальных услуг «Мои документы» и планшетов, которые заполнят переписчики ${ }^{10}$. При этом переход к цифровому сбору информации позволил снизить расходы на проведение ВПН2020 с 60 до 32 миллиардов рублей ${ }^{11}$, а время на заполнение анкеты сократить в среднем до 23 минут - практически вдвое по сравнению с пробной переписью 2018 года ${ }^{12}$.

Следующим примером применения цифровых технологий в регионах является проект «Цифровой Водоканал». Акционерное общество «Цифровые платформы и решения Умного Города» ${ }^{13}$ (Государственная корпорация «Росатом»), разрабатывающая проекты по цифровизации муниципального и регионального управления, выдвинула проект «Разработка программных модулей информационной системы «Цифровой Водоканал», цель которого - повышение эффективности производственной деятельности предприятий водоснабжения и водоотведения за счет производственных и технологических показателей ${ }^{14}$. Проект позволяет снизить время на ре-

5 Как российские регионы развивают цифровую экономику от 20.08.2018. Ведущее государственное информационное агентство Российской Федерации «TACС» [Электронный ресурc]. URL: https://tass.ru (дата обращения: 02.10.2021 г.).

645 тысяч переписчиков, дроны и спутниковый мониторинг: в Росстате проанализировали ход сельскохозяйственной микропереписи 2021 года от 08.09.2021 [Электронный ресурc]. URL: https://rosstat.gov.ru/folder/313/ document/133753 (дата обращения: 02.10.2021 г.).

7 Портал дистанционного электронного голосования [Электронный ресурc]. URL: https://vybory.gov.ru (дата обращения: 21.09.2021 г.).

8 Центральная избирательная комиссия Российской Федерации [Электронный ресурc]. URL: http://cikrf.ru (дата обращения: 21.09.2021 г.).

9 Портал Всероссийской переписи населения [Электронный ресурс]. URL: https://strana2020.ru (дата обращения: 21.09.2021 г.).

10 Федеральная служба государственной статистики (Росстат) [Электронный ресурc]. URL: https://rosstat. gov.ru (дата обращения: 24.09.2021 г.).

11 Подготовка к Всероссийской переписи населения вышла на финишную прямую от 24.09.2021 [Электронный ресурс]. URL: https://rosstat.gov.ru/folder/313/document/135743 (дата обращения: 02.10.2021 г.).

12 Переписаться за 23 минуты от 29.09.2021 [Электронный ресурc]. URL: https://rosstat.gov.ru/folder/313/ document/136664 (дата обращения: 02.10.2021 г.).

13 Акционерное общество «Цифровые платформы и решения Умного Города» [Электронный ресypc]. URL: https://rosatom.city (дата обращения: 01.10.2021 г.).

14 Акционерное общество «Русатом Инфраструктурные решения» дивизион Госкорпорации «Росатом» [Электронный ресурc]. URL: https://rusatom-utilities.ru (дата обращения: 01.10.2021г.). 
агирование повреждений на $15 \%$ и возникновение нештатных ситуаций до $25 \%$, увеличить производительность труда до 45\%, повысить энергетическую эффективность до $15 \%$ и производительность труда сотрудников на 61\%, при этом увеличить рост начислений за бездоговорное потребление до $70 \%$. В настоящий момент данный проект реализован в 24 городах и реализуется в 8 городах России.

Также компания помогает городам в достижении Целей устойчивого развития с помощью применения и разработки цифровых решений [1]. Так, компания внедрила проекты «Умный Саров» и «Умный Железноводск», которые стали победителями конкурса Правительства Российской Федерации «Лучшая муниципальная практика» в 2020 году. Помимо этого, в рамках проекта «Умный регион» в настоящий момент 23 субъекта реализуют программу «Эффективный регион» на основе бережливых технологий, 5 субъектов реализуют проекты по цифровой трансформации секторов экономики на базе решений Госкорпорации, а 19 «атомных» городов внедряют технологию «Бережливый умный город».

Вместе с тем компания разработала туристический веб-портал, который позволяет муниципалитету и бизнесу собирать статистические данные для использования в работе на основе планов и маршрутов путешествия туристов, платформу «Умный транспорт» для мониторинга состояния дорожных покрытий, управления общественным транспортом, обеспечения транспортной безопасности, моделирования транспортных потоков, метео-мониторинга и других решений, систему мониторинга уборки территорий муниципальных образований и интеллектуальную систему состояния объектов городского хозяйства, дворовых и общественных территорий Мурманской области, «Цифровую платформу развития Томской области» ${ }^{15}$.

Отличительным проектом «Росатома» стал первый в Российской Федерации «умный город-курорт» Железноводск, который стал пилотным проектом по синхронизации туристических сервисов и городских ресурсов. Проект включает создание мобильного приложения, сайта, 12 смарт-панелей, уста- новленных на улицах города, «умные остановки» и «умные переходы».

В области достижения Целей устойчивого развития стоит отметить также проект ООО «Управляющая компания «Предприятие жилищно-коммунального хозяйства», входящий в группу компаний «РТ-Инвест», по внедрению «умных» датчиков на контейнерах для сбора твердых коммунальных отходов, автотранспорте и полигонах хранения и переработки. Проект подразумевает под собой эксплуатацию программно-аппаратной платформы, которая обрабатывает и анализирует данные с датчиков в режиме реального времени. Данная технология дает возможность дистанционно отследить наполненность контейнеров и в случае необходимости уведомляет операторов для направления мусоровоза на территорию. Так, в городе Казани действует более 5 тысяч площадок по сбору ТКО с 12 тысячами «умных» контейнеров, что позволило внедрить раздельный сбор в более чем $80 \%$ дворов и вдвое увеличить долю перерабатываемых отходов.

Выводы по результатам исследования. Проанализировав использование цифровых технологий в субъектах России, можно прийти к выводу об увеличивающемся росте цифровизации регионов и достижении определенного успеха в применении цифровых ресурсов. Многие компании видят потенциал российских регионов и перспективы для реализации цифровых проектов, однако существующий разрыв между субъектами в области внедрения цифровых технологий и в области цифрового развития замедляет общий процесс. При этом существенной становится проблема нехватки квалифицированных специалистов для реализации программ цифровой экономики, так как они являются основным средством цифровой трансформации. В связи с этим в настоящий момент в рамках национального проекта решается вопрос привлечения кадров для цифровой экономики. Следовательно, для достижения цифровой трансформации необходимо принимать меры по устранению цифрового разрыва путем взаимодейс-

15 Цифровая платформа развития Томской области [Электронный ресурс]. URL: https://tomsk.life (дата обращения: 01.10.2021 г.). 
Вестник ЮРГТУ (НПИ). Серия: Сочиально-экономические науки. 2021 г. T. 14. № 6 Bulletin of the SRSTU (NPI). Series: Socio-Economic Sciences. 2021. Vol. 14. № 6

твия и передачи опыта ведущих регионов, а также развивать цифровой спрос и предложение, например, с помощью увеличения таких ресурсов, как «Россия - страна возможностей» ${ }^{16}$ и «Российский фонд развития информационных технологий» (РФРИТ $)^{17}$.

\section{Список источников}

1. Абдрасилова Г.С. Цифровизация экономики и цифровая среда современной архитектуры // Биосферная совместимость: человек, регион, технологии. 2019. №1. С. 4-13.

2. Авдеева И.Л. Анализ перспектив развития цифровой экономики в России и за рубежом // Цифровая экономика и «Индустрия 4.0»: проблемы и перспективы. Труды науч.практ. конференции с международным участием. 2017. С. 10-19.

3. Алексеенко О.А. Цифровизация глобального мира и роль государства в цифровой экономике // Информационное общество. 2018. №2. C. 25-28.

4. Бабкин А. В. Формирование цифровой экономики в России: сущность, особенности, техническая нормализация, проблемы развития // Научно-технические ведомости СанктПетербургского государственного политехнического университета. Экономические науки. 2017. Т. 10. №3. С. 11-22.

5. Бехер В.В. Цифровые технологии: угрозы и риски внедрения // Евразийское Научное Объединение. 2019. Т. 3. №1(47). С. 145-146.

6. Бодрунов С. Д., Демиденко Д. С., Плотников В.А. Реиндустриализация и становление «цифровой экономики»: гармонизация тенденций через процесс инновационного развития // Управленческое консультирование. 2018. №2. С. 43-54.

7. Плотников В.А. Цифровизация производства: теоретическая сущность и перспективы развития в российской экономике // Известия Санкт-Петербургского государственного экономического университета. 2018. №4(112). C. 16-24.

8. Попов Е.В. Умные города: монография. М.: Издательство Юрайт, 2020. С. 112-156.
9. Попов Е.В. Приоритеты экономической политики в развитии цифровой экономики // Национальные интересы: приоритеты и безопасность. 2019. Т. 13. №7. С. 1198-1214.

10. Устюжанина Е.В. Цифровая экономика как новая парадигма экономического развития // Национальные интересы: приоритеты и безопасность. 2017. Т. 13. №10. С. 1788-1804.

11. Цели устойчивого развития в Российской Федерации. Краткий статистический бюллетень / Росстат. М., 2020. С. 52-57.

12. Шарандина Н. Л. Цифровая экономика как приоритетная национальная цель развития Российской Федерации: правовой аспект // Финансовое право. 2018. №9. С. 15-19.

\section{References}

1. Abdrasilova G.S. Cifrovizacija jekonomiki i cifrovaja sreda sovremennoj arhitektury [Digitalization of the economy and the digital environment of modern architecture]. $\mathrm{Bi}$ osfernaja sovmestimost': chelovek, region, tehnologii [Biosphere compatibility: man, region, technologies]. 2019; (1): 4-13. (In Russ.).

2. Avdeeva I.L. Analiz perspektiv razvitija cifrovoj jekonomiki v Rossii i za rubezhom [Analysis of prospects for the development of the digital economy in Russia and abroad]. Cifrovaja jekonomika i «Industrija 4.0»: problemy i perspektivy. Trudy nauch.-prakt. konferencii s mezhdunarodnym uchastiem [Digital Economy and «Industry 4.0»: problems and prospects. Proceedings of the scientific and practical conference with international participation]. 2017. P. 10-19. (In Russ.).

3. Alekseenko O.A. Cifrovizacija global'nogo mira i rol' gosudarstva $\mathrm{v}$ cifrovoj jekonomike [Digitalization of the global world and the role of the state in the digital economy]. Informacionnoe obshhestvo [Information Society]. 2018; (2): 25-28. (In Russ.).

4. Babkin A.V. Formirovanie cifrovoj jekonomiki v Rossii: sushhnost', osobennosti, tehnicheskaja normalizacija, problemy razvitija [Formation of the digital economy in Russia: essence, features, technical normalization, development problems]. Nauchno-tehnicheskie vedo-

16 Автономная некоммерческая организация «Россия - страна возможностей» [Электронный ресурс]. URL: https://rsv.ru (дата обращения: 24.09.2021 г.).

17 Российский фонд развития информационных технологий [Электронный ресypc]. URL: https://pфрит.pф (дата обращения: 01.10.2021 г.). 
mosti Sankt-Peterburgskogo gosudarstvennogo politehnicheskogo universiteta. Jekonomicheskie nauki [Scientific and Technical Bulletin of St. Petersburg State Polytechnic University. Economic sciences]. 2017; 10(3): 11-22. (In Russ.).

5. Beher V. V. Cifrovye tehnologii: ugrozy i riski vnedrenija [Digital technologies: threats and risks of implementation]. Evrazijskoe Nauchnoe Ob'edinenie [Eurasian Scientific Association]. 2019; 3(1(47)): 145-146. (In Russ.).

6. Bodrunov S.D., Demidenko D.S., Plotnikov V.A. Reindustrializacija i stanovlenie «cifrovoj jekonomiki»: garmonizacija tendencij cherez process innovacionnogo razvitija [Reindustrialization and the formation of the «digital economy»: harmonization of trends through the process of innovative development]. Upravlencheskoe konsul'tirovanie [Managerial consulting]. 2018; (2): 43-54. (In Russ.).

7. Plotnikov V.A. Cifrovizacija proizvodstva: teoreticheskaja sushhnost' i perspektivy razvitija $\mathrm{v}$ rossijskoj jekonomike [Digitalization of production: theoretical essence and prospects of development in the Russian economy]. Izvestija Sankt-Peterburgskogo gosudarstvennogo jekonomicheskogo universiteta [News of St. Petersburg State University of Economics]. 2018; 4(112): 16-24. (In Russ.).
8. Popov E. V. Umnye goroda: monografija [Smart cities: a monograph]. Moscow: Izdatel'stvo Jurajt, 2020. P. 112-156. (In Russ.).

9. Popov E.V. Prioritety jekonomicheskoj politiki v razvitii cifrovoj jekonomiki [Priorities of economic policy in the development of the digital economy]. Nacional'nye interesy: prioritety $i$ bezopasnost' [National interests: priorities and security]. 2019; 13(7): 1198-1214. (In Russ.).

10. Ustjuzhanina E.V. Cifrovaja jekonomika kak novaja paradigma jekonomicheskogo razvitija [Digital economy as a new paradigm of economic development]. Nacional'nye interesy: prioritety $i$ bezopasnost' [National interests: priorities and security]. 2017; 13(10): 1788-1804. (In Russ.).

11. Celi ustojchivogo razvitija v Rossijskoj Federacii. Kratkij statisticheskij bjulleten' [Sustainable Development Goals in the Russian Federation. Brief Statistical Bulletin]. Rosstat. Moscow, 2020. P. 52-57. (In Russ.).

12. Sharandina N.L. Cifrovaja jekonomika kak prioritetnaja nacional'naja cel' razvitija Rossijskoj Federacii: pravovoj aspekt [Digital economy as a priority national development goal of the Russian Federation: a legal aspect]. Finansovoe pravo [Financial Law]. 2018; (9): 15-19. (In Russ.).

Статья поступила в редакцию 04.12.2021; одобрена после рецензирования 08.12.2021; принята к публикации 18.12.2021.

The article was submitted on 04.12.2021; approved after reviewing on 08.12.2021; accepted for publication on 18.12.2021.

\section{ИНФОРМАЦИЯ ОБ АВТОРАХ}

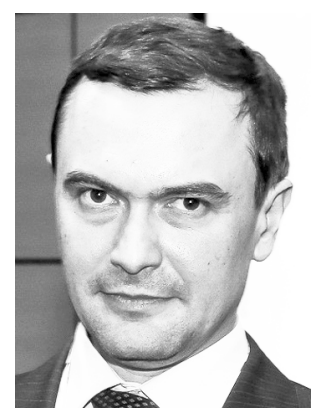

Куликов Михаил Михайлович - кандидат экономических наук, доцент, Южно-Российский государственный политехнический университет (НПИ) имени М.И. Платова. Сфера научных интересов - промышленная политика, кластеры в экономике, цифровая трансформация экономики, управление персоналом.

Россия, г. Новочеркасск, ул. Просвещения, 132

Mikhail M. Kulikov - Candidate of Economic Sciences, Associate Professor, Platov South Russian State Polytechnic University (NPI). Research interests - industrial policy, clusters in the economy, digital transformation of the economy, personnel management.

132 Prosveshcheniya st., Novocherkassk, Russia 


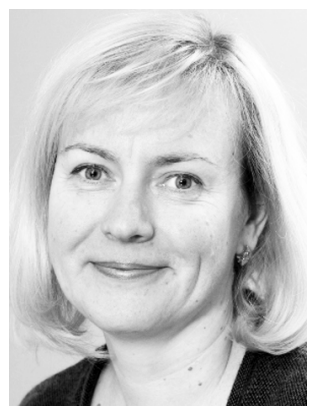

Комиссарова Мария Анатольевна - доктор экономических наук, профессор, доцент, заведующий кафедрой «Производственный и инновационный менеджмент», Южно-Российский государственный политехнический университет (НПИ) имени М.И. Платова. Разработчик проекта «Теория, методика и технологии профессионального образования по направлениям подготовки соответствующим приоритетным направлениям модернизации и технологического развития российской экономики». Сфера научных интересов - стратегическое управление промышленными предприятиями, проблемы функционирования предприятий в структуре Российского топливно-энергетического комплекса.

Россия, г. Новочеркасск, ул. Просвещения, 132

Maria A. Komissarova - Doctor of Economic Sciences, Professor, Head of the Department of Production and Innovation Management, Platov South Russian State Polytechnic University (NPI). Creator of the project «Theory, methodology and technology of vocational education in the areas of training corresponding to the priority areas of modernization and technological development of the Russian economy». Research interests - strategic management of industrial enterprises; problems of enterprises functioning in the structure of the Russian fuel and energy complex.

132 Prosveshcheniya st., Novocherkassk, Russia

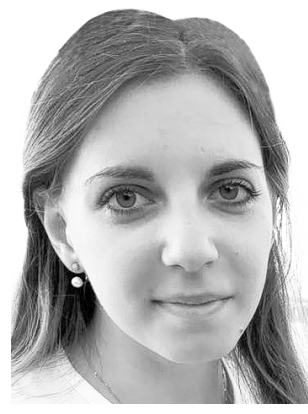

Комарова Алина Владимировна - студент Южно-Российского государственного политехнического университета (НПИ) имени М.И. Платова.

Россия, г. Новочеркасск, ул. Просвещения, 132

Alina V. Komarova — Student, Platov South Russian State Polytechnic University (NPI).

132 Prosveshcheniya st., Novocherkassk, Russia

\section{Вклад авторов:}

Куликов М.М. - научное руководство; концепция исследования; развитие методологии; написание исходного текста; итоговые выводы.

Комиссарова М. А. - разработка инструментария исследования; проведение исследования; обработка результатов.

Комарова А. В. - проведение исследования; обработка результатов.

Contribution of the authors:

Kulikov M.M. - scientific guidance; research concept; development of methodology; writing of the source text; final conclusions.

Komissarova M.A. - development of tools for sociological research; conducting research; processing results.

Komarova A. V. - conducting research; processing the results. 